\title{
Periodontal disease and women reproductive health
}

\begin{abstract}
Periodontal diseases (PDs) include a group of inflammatory diseases characterized by periodontium hard and soft tissues destruction leading to host immune response activation. It has been suggested that bacterial infection-induced direct tissue damages along with indirect effects of host immune responses play roles in pathogenesis of PDs. Increasing numbers of reports have provided strong evidence that there is a potential association between maternal PDs and delivery of preterm low birth weight infants. Moreover, having PDs during pregnancy has been linked with an increased risk for preeclampsia. Previous reports have also exhibited that PDs are associated with significant higher percentage of endometriosis and maternal PDs can affect the effectiveness of infertility therapies and in vitro fertilization success. Increased levels of inflammatory mediators including PGE2 and TNF due to lipopolysaccharides production by periodontopathic bacteria have been attributed to adverse pregnancy outcomes. Since PDs may increase the risk of perinatal mortality and developmental disorders as well as infertility treatments failure, oral health promotions through wellorganized strategies should be prioritized particularly in mothers-to-be.
\end{abstract}

Volume 7 Issue 2 - 2018

\author{
Ali Shalizar Jalali \\ Department of Basic Sciences, Faculty of Veterinary Medicine, \\ Iran \\ Correspondence: Ali Shalizar Jalali, VMD, PhD, Histology \\ and Embryology Research Laboratories, Department of Basic \\ Sciences, Faculty of Veterinary Medicine, Urmia University, \\ Urmia, Iran, Fax 00984432771926, Tel 00984431942593, \\ Email ali_shalizar@yahoo.com, a.shalizar@urmia.ac.ir
}

Received: March 01, 2018 | Published: April 17, 2018

Keywords: periodontium, endometriosis, pregnancy, fertilization

\section{Mini review}

Periodontium as a tooth supporting apparatus is composed of hard tissues (cementum and alveolar bone) as well as vascularized soft tissues (gingiva and periodontal ligament) and its homeostasis is associated with complex multifactorial relationships. ${ }^{1,2}$ Periodontal diseases (PDs) include a group of inflammatory diseases characterized by periodontium hard and soft tissues destruction leading to host immune response activation. ${ }^{3}$ It has been reported that PDs as one of the two biggest threats to the oral health have a high prevalence in United States and they have been found in nearly half (45.9\%) of the population aged 30 years and older. ${ }^{4,5}$ Further, it has been revealed that PDs affect up to $15 \%$ of the population of childbearing age and some degrees of PDs can be seen in relatively high proportions of pregnant women. ${ }^{6}$ It has been suggested that bacterial infection-induced direct tissue damages along with indirect effects of host immune responses play roles in pathogenesis of PDs. ${ }^{7}$ Increasing numbers of reports have provided strong evidence that there is a potential association between maternal PDs and delivery of preterm low birth weight (PLBW) infants. ${ }^{89}$ Accordingly, it has been indicated that lower risk for low birth weight infants can be observed in mothers with healthy gingiva. ${ }^{10}$

Moreover, having PDs during pregnancy has been linked with an increased risk for preeclampsia. ${ }^{11}$ Also, it has been shown that PDs treatment during pregnancy can result in PLBW infant rates reduction. ${ }^{12}$ Increased levels of inflammatory mediators including PGE2 and TNF due to lipopolysaccharides production by periodontopathic bacteria have been attributed to adverse pregnancy outcomes. ${ }^{13}$ Additionally, it has been suggested that PDs-induced gonadotrophin-releasing and luteinizing hormones levels reductions can result in ovulation failure. ${ }^{14}$ Previous reports have also exhibited that PDs are associated with significant higher percentage of endometriosis ${ }^{15}$ and maternal PDs can affect the effectiveness of infertility therapies and in vitro fertilization success. ${ }^{16}$ Reportedly, PDs can also increase a woman's time to conception. ${ }^{17}$ In general, since PDs may increase the risk of perinatal mortality and developmental disorders as well as infertility treatments failure (Figure 1), oral health promotions through well- organized strategies including regular preventive dental check-ups as well as lifestyle modifications should be prioritized particularly in mothers-to-be.

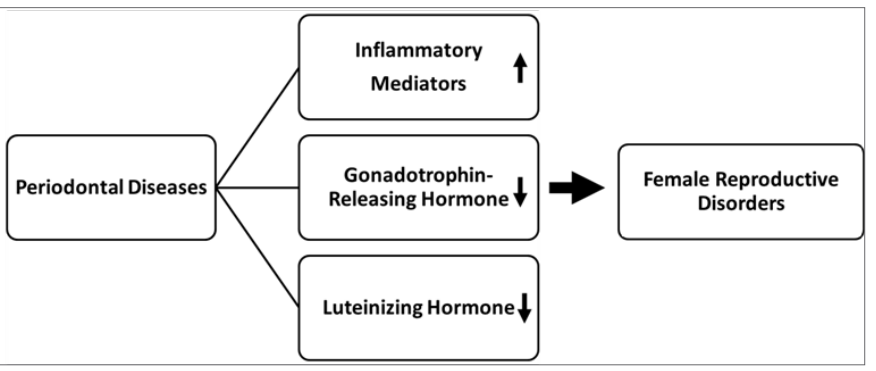

Figure I Possible association between periodontal diseases and female reproductive disorders.

\section{Acknowledgment}

None.

\section{Conflict of interest}

None.

\section{References}

1. Barczyk M, Bolstad AI, Gullberg D. Role of integrins in the periodontal ligament: organizers and facilitators. Periodontol 2000. 2013;63(1):2947.

2. Güncü GN, Tözüm TF, Cağlayan F. Effects of endogenous sex hormones on the periodontium-review of literature. Aust Dent J. 2005;50(3):138-45.

3. Tsuchida S, Satoh M, Takiwaki M, et al. Ubiquitination in periodontal disease: a review. Int J Mol Sci. 2017;18(7):1476.

4. Eke PI, Dye BA, Wei L, et al. Update on prevalence of periodontitis in adults in the United States: NHANES 2009 to 2012. J Periodontol. 2015;86(5):611-22. 
5. Benjamin RM. Oral health: the silent epidemic. Public Health Rep. 2010;125(2):158-9.

6. Boggess KA, Edelstein BL. Oral health in women during preconception and pregnancy: implications for birth outcomes and infant oral health. Matern Child Health J. 2006;10:169-74.

7. Genco RJ. Host responses in periodontal diseases: current concepts. $J$ Periodontol. 1992;63(4 Suppl):338-55.

8. Offenbacher S, Katz V, Fertik G, et al. Periodontal infection as a possible risk factor for preterm low birth weight. J Periodontol. 1996;67:1103-13.

9. Gandhimadhi D, Mythili R. Periodontal infection as a risk factor for preterm low birth weight. J Indian Soc Periodontol. 2010;14(2):114-20.

10. Dasanayake AP. Poor periodontal health of the pregnant woman as a risk factor for low birth weight. Ann Periodontol. 1998;3(1):206-12.

11. Boggess KA, Lieff S, Murtha AP, et al. Maternal periodontal disease is associated with an increased risk for preeclampsia. Obstet Gynecol. 2003;101(2):227-31.
12. López NJ, Smith PC, Gutierrez J. Periodontal therapy may reduce the risk of preterm low birth weight in women with periodontal disease: a randomized controlled trial. J Periodontol. 2002;73(8):911-24.

13. Offenbacher S, Jared HL, O'Reilly PG, et al. Potential pathogenic mechanisms of periodontitis associated pregnancy complications. Ann Periodontol. 1998;3(1):233-50.

14. Fogacci MF, da Silva Barbirato D, Rodrigues MO, et al. Periodontitis and infertility: an evidence-based review. Glob J Fertil Res. 2016;1(1):011-5.

15. Kavoussi SK, West BT, Taylor GW, et al. Periodontal disease and endometriosis: analysis of the National Health and Nutrition Examination Survey. Fertil Steril. 2009;91(2):335-42.

16. Pavlatou A, Dokou P, Tsami A. Periodontal disease, infertility treatment and in vitro fertilization (IVF). J Fertil in vitro IVF Worldw Reprod Med Genet Stem Cell Biol. 2015;3:148.

17. Nwhator SO, Opeodu OI, Ayanbadejo PO, et al. Could periodontitis affect time to conception? Ann Med Health Sci Res. 2014;4(5):817-22. 